\title{
Mixed methods research in global education: Towards a new paradigm for global citizenship education
}

\author{
Sadiq Abubakar, Abdullahi, Mohammed Kabiru, Farouk \\ Department of Education, Federal University Kashere, Gombe, Nigeria \\ Email address: \\ aabdu101@yahoo.com (S. A. Abdullahi),mkfarouk@fukashere.ed.ng (M. K. Farouk)
}

\section{To cite this article:}

Sadiq Abubakar, Abdullahi, Mohammed Kabiru, Farouk. Mixed Methods Research in Global Education: Towards a New Paradigm for Global Citizenship Education. International Journal of Secondary Education. Vol. 2, No. 3, 2014, pp.52-60.

doi: 10.11648/j.ijsedu.20140203.12

\begin{abstract}
This empirical study in global education was conducted over a decade ago at a time when the Mixed Methods Research (MMR) methodology, a new paradigm in education research, was emerging. The global education research community was slow to this new phenomenon. This paper discusses MMR as a viable alternate method of inquiry in global education research. The paper contributes to the discourse and promotes the values of MMR in global education research. The study combines quantitative and qualitative research elements to answer critical questions about secondary school teachers' lack of global knowledge, global mindedness, and teaching skills. Secondary school teachers' lack of global education undermines their ability to develop programs and activities that will become the foundation for local and national consciousness for global engagement and community service activism. The MMR becomes a metaphor for a new concept in global citizenship education, in a complex, rapidly changing world, where students continually see themselves and the world through the lenses of human abuses, insecurity, prejudice and intolerance leading to various violent and destructive engagements.
\end{abstract}

Keywords: Global Education, Secondary Education, Global Mindedness, Mixed Methods Research, Qualitative Research, Quantitative Research, and Global Pedagogy

\section{Introduction}

As the global community approaches the end of the first quarter of the $21^{\text {st }}$ century (2000-2025), it faces serious social, cultural, environmental, political, technological, and economic challenges. Political and policy-making leaders, activists, international non-governmental organizations (INGOs), local non-governmental organizations (NGOs), interfaith organizations, and educational researchers around the world continue to search for solutions to the seemingly intractable issues and problems of conflict of interest, resource sharing and value systems facing the world (Abdullahi, 2004, 2010; Zajda, 2010 ).

Since the September 11, 2001 terrorist attack in the United States, for example, many nations have made deliberate attempts secure their nations by making them safer politically, economically, politically, environmentally, and now educationally through the promotion of global or international education. The United Nations through the Secretary-General's Global Education First Initiative, has identified three priorities. The first is "Every Child in
School." The second is "Quality of Learning." The third is "Global Citizenship." The United States and nations such as Great Britain, Australia, China, Russia, and Japan are taking the concepts of global or international education and global citizenship very seriously to the extent that adjustments in their foreign policy objectives are now shifting from military force to diplomatic, normative, and qualitative engagement (Gutek, 2006). The idea is that to address national security threats posed by economic problems and religious extremism. Political, environmental, socio-cultural, and economic instability around the world has led to all sorts of social unrests and many prolonged ethnic and religious conflicts around the world (Abdullahi, 2010). In the wake of the September 11, 2001 attacks, the then U.S. Secretary of State, Colin Powell, said that Americans must be engaged now more than ever before with the rest of the world. Three years after the attacks in New York and Washington, D.C., it has become increasingly urgent to promote global or international education in schools locally and globally.

As a result, many educational institutions and 
international development agencies, in the affected countries, have increased educational research to explain the cause and effect of global issues and problems. Environmental pollution, global warming, globalization, and global terrorism continue to pose the most threat to securing our global future and the Planet. Global education research in MMR offers a viable alternative to traditional qualitative or quantitative research methodology (Abdullahi, 2010).

A mixed methods design that combined quantitative and qualitative data was used. ANOVA and Chi square techniques were used to determine whether the factors that contributed to teachers' global knowledge and global mindedness differ among groups. Classroom observations and interviews were conducted to determine whether the instructional strategies differ among the seven selected teachers.

\subsection{Contextual Background}

The current global realities, such as global warming, environmental pollution, population growth, hunger, refugees, poverty, conflicts, unemployment and inflation, diseases, abuses in human rights and social justice, the lack of widespread understanding of how democracy works, the problem of greed and corruption, intolerance, religious extremism, and the proliferation of nuclear weapons can be addressed when governments reach the hearts and minds of people and that some of the major global problems facing the world require considerable collective institutional and human effort (Gutek, 2006; Zajda, 2005).

Many qualitative and quantitative comparative studies have presented evidence that teachers at the secondary school level have the best chance to influence global thinking and local engagement, but they lack the understanding of how global events, issues, and problems are interrelated or interconnected, or how global systems and institutions are interdependent and how the issues and problems impact our individual and collective ability to preserve and secure the Planet (Abdullahi, 2010; American Forum for Global Education, 2002; Anderson, 1990; Kirkwood, 2001; Merryfield, 1997; Tucker, 1983).

In many secondary schools around the world, social studies teachers have the primary responsibility to raise the awareness of global issues, problems, and events in the classroom. Therefore, for social studies teacher educators, the challenge lies in helping teachers develop a consciousness in order to help their students to become interested in learning more about the world. As a former professional tennis player who travelled around the world, now a social science researcher, I was deeply concerned that many teachers lack the prerequisite global knowledge, global mindedness, and the attitude needed to secure our national and global future. This lack of knowledge of the world, as not being only a small, interdependent and interconnected global village, but even more significantly the lack of knowledge of the relative impact on the local village, setting the stage for increasingly hostile and violent attacks on children, cultures, people and property as seen in north eastern part of Nigeria with the Boko Haram insurgency and the senseless kidnapping of innocent girls. Furthermore, this lack of global knowledge, global mindedness, and attitude has serious local consequences. Global teacher educators understand that teachers and students must become more responsive to global issues and problems. Therefore, because of their position within secondary schools, social studies teachers must have the global knowledge, global mindedness, and pedagogical training needed to help students to understand how these phenomena can destroy the Planet and our collective humanity.

The global community is facing serious challenges brought on by technological advancement, environmental degradation, and globalization. To help address these $21 \mathrm{st}$ century global challenges, we are arguing that before secondary school students graduate from secondary schools, they must develop a mindset and a communication, negotiation, critical, creative, and reflective thinking skills. They should also develop their analytical and interpretive skills to address emerging local, regional and global issues and problems (Kirkwood, 2001; Merryfield, 2001; Tashakkori, \& Teddlie. (1998).).

\section{Purpose and Problem of the Study}

The purpose of this study was to examine the factors that contribute to teachers' global knowledge, global mindedness, and pedagogy concerning global education and how this can be better imparted to their students to promote global understanding, global engagement, and conflict resolution and peace through global citizenship education. The problem investigated was secondary school teachers' lack of global knowledge, global mindedness, and pedagogy of global education.

\subsection{Research Questions}

The following research questions were addressed in this study:

1. Is there a significant difference among teachers trained in Globally Oriented Social Studies Education (GOSSE), trained in non-Globally Oriented Social Studies education (non-GOSSE), and Teachers Who Teach Other Subjects (TWTOS) groups in their teaching of global knowledge and global mindedness within the school system?

2. Is there a significant difference between teachers in the GOSSE group and the non-GOSSE/TWTOS group in terms of their global knowledge and global mindedness?

3. Is there a significant difference between teachers in GOSSE/non-GOOSE and TWTOS groups in their global knowledge and global mindedness?

4. Is there a relationship between age, gender, and years of teaching experience in teachers' global knowledge and global mindedness? 
5. Do teachers from the GOSSE group teach from a global perspective and infuse global perspectives into the curriculum differently than do teachers from the non-GOSSE group?

\section{Assumptions}

The basic assumptions of this study were:

1. Global education, global citizenship, and globalization are interconnected, interrelated, and interdisciplinary concepts.

2. Teachers' responses to the survey instruments used in this study reflect their authentic global knowledge, understanding, and awareness. Authentic in this study refers to teachers' true knowledge and understanding of the issues and problem facing the world.

3. Understanding of the importance of global education, global citizenship, and globalization and their linkages will make a difference in the development of teachers' global pedagogical strategies and attitudes.

4. Global education, global citizenship, and globalization processes impact many sectors in society especially those involving politics, the environment, the economy, technology, culture, and education.

5. Global education and global citizenship have a moral and ethical compass and purpose (Abdullahi, 2010, Kirkwood, 2001).

6. Social studies teachers should use a conceptual framework or model to teach from a global perspective.

7. The extent to which social studies teachers teach from a global perspective is influenced by the kind of training they receive.

\subsection{Limitations of the Study}

Only high school teachers participated in the study. Therefore, caution should be taken concerning generalizing study findings from them to elementary and middle school teachers in M-DCPS. Another limitation was the small number of classroom observations. Only seven social studies teachers were observed. The viewpoints of these teachers cannot be said to totally represent the views of all social studies teachers in the school district. Another limitation was the inherently subjective nature of the classroom observation interpretations.

\subsection{Demographic Data}

Miami-Dade County Public Schools (M-DCPS) is the fourth largest school district in the nation and employs approximately 800 secondary social studies teachers, who teach students from different countries and different cultural backgrounds. A total of 90 secondary teachers from Miami-Dade County Public Schools were randomly selected and placed in three groups: Globally Oriented Social Studies Program (GOSSE), Non-Globally Oriented Social Studies Program (non-GOSSE), and Teachers Who
Teach Other Subjects (TWTOS). Seven teachers, two of whom team-taught a class, were selected for classroom observations and interviews. Group 1 consisted of teachers who had attended a globally oriented social studies education program (GOSSE). Teachers in this group have taken a preparatory course on how to teach from a global perspective at FIU in the College of Education. Group 2 consisted of teachers from other programs or other institutions' social studies education programs (nonGOSSE). Group 3 consisted of teachers who teach other subjects such as language arts, science, math, and ESOL (TWTOS). The researcher believes that teachers in Group 3 can contribute to students' global knowledge and global understanding, because adding a global dimension or teaching from a global perspective is not limited only to social studies teachers. Significance of the Study

This study will help those and other teachers become more aware of a range of appropriate instructional strategies for teaching from a global perspective. The demographic data for Age, Gender, Ethnicity, and Years of Teaching Experience are presented in Table 1.

Table 1. Participant Demographic Data $(n=90)$

\begin{tabular}{|c|c|c|c|c|c|c|}
\hline \multirow{2}{*}{ Variable } & \multicolumn{2}{|c|}{ GOSSE } & \multicolumn{2}{|c|}{ Non-GOSSE } & \multicolumn{2}{|c|}{ TWTOS } \\
\hline & $n$ & $\%$ & $n$ & $\%$ & $N$ & $\%$ \\
\hline \multicolumn{7}{|l|}{ Age } \\
\hline $20-30$ & 8 & 27 & 12 & 40 & 7 & 23 \\
\hline $31-40$ & 5 & 17 & 5 & 17 & 11 & 37 \\
\hline $41-50$ & 8 & 27 & 11 & 37 & 9 & 30 \\
\hline $50+$ & 9 & 30 & 2 & 7 & 3 & 10 \\
\hline \multicolumn{7}{|l|}{ Gender } \\
\hline Female & 12 & 40 & 18 & 60 & 18 & 60 \\
\hline Male & 18 & 60 & 12 & 40 & 12 & 40 \\
\hline \multicolumn{7}{|l|}{ Ethnicity } \\
\hline White & 8 & 27 & 2 & 7 & 4 & 13 \\
\hline Black & 2 & 7 & 1 & 3 & 3 & 10 \\
\hline Hispanic & 12 & 40 & 8 & 27 & 4 & 13 \\
\hline Other & 8 & 27 & 19 & 63 & 19 & 63 \\
\hline \multicolumn{7}{|c|}{ Years of Teaching Experience } \\
\hline $0-10$ & 14 & 47 & 21 & 21 & 19 & 63 \\
\hline $11-20$ & 16 & 53 & 9 & 30 & 11 & 37 \\
\hline \multicolumn{7}{|l|}{ Degree } \\
\hline Bachelors & 10 & 33 & 11 & 37 & 12 & 12 \\
\hline Masters & 10 & 33 & 10 & 33 & 10 & 33 \\
\hline Specialist & 6 & 20 & 9 & 30 & 6 & 20 \\
\hline Doctoral & 4 & 13 & 1 & 3 & 2 & 6 \\
\hline
\end{tabular}

In the Miami-Dade County School district, all elementary and secondary school teachers are required to add multicultural and global dimensions in their classroom instruction. Teachers, who participated in this study represented the diverse multicultural backgrounds found in Miami-Dade County School district. Female teachers 
represented $53 \%$ of the sample, while $47 \%$ were male. Twenty seven percent of the participants were Hispanic. Fifteen percent were White, and seven percent were Black. Sixty percent of the participants had less than 10 years of teaching experience. Forty percent had more than 10 years of teaching experience. Thirty seven percent of the participants had a bachelor's degree. Thirty three percent of the participants had a master's degree. Twenty three percent had a specialist degree. Seven percent had a doctoral degree. The Chi-square test shows that there is no significant difference between the age, gender, and ethnicity of the participants and the participants' global knowledge and global mindedness. The analysis of the quantitative data is presented in the next section.

\subsection{Analysis of Quantitative Data}

This part of the study was designed to answer four quantitative research questions:

a) Is there a difference among teachers in GOSSE, nonGOSSE, and TWTOS programs in their global thinking (i.e. global knowledge and global mindedness)?

b) Is there a difference between teachers in GOSSE and in both non-GOSSE and TWTOS programs in their global thinking?

c) Is there a difference between teachers in both GOSSE and non-GOSSE and TWTOS programs in their global thinking?

d) Is there a relationship between degree, age, gender, and years of teaching experience in teachers' global thinking?

The summary of means and standard deviations of global thinking by groups is presented in Table 2 .

Table 2. Summary Table of Means and Standard Deviation of Global Thinking by Group Membership

\begin{tabular}{lllll}
\hline \multirow{2}{*}{ Group } & \multicolumn{2}{l}{ Global Mindedness } & \multicolumn{2}{l}{ Global Knowledge } \\
\cline { 2 - 5 } & $\boldsymbol{M}$ & $\boldsymbol{S D}$ & $\boldsymbol{M}$ & $\boldsymbol{S D}$ \\
\hline GOSSE & 48.86 & 10.51 & 54.66 & 10.66 \\
Non-GOSSE & 51.65 & 10.02 & 45.51 & 9.64 \\
TWTOS & 49.48 & 9.56 & 49.82 & 7.84 \\
\hline
\end{tabular}

Because the instrument was modified, the norms set for the unmodified instrument would not be appropriate. Therefore, the overall average of raw scores for the group $(M=26.72, S D=6.89)$ was used as the reference to determine the average. The standardization of the data results in this average translating to a score of 50 with a standard deviation of 10 .

As shown in Table 2, the standardized means and standard deviations for global mindedness and global knowledge revealed that the means for global mindedness range from 48.86 to 51.65 and the standard deviations range from 9.56 to 10.51 , indicating that the variances are not significantly different from each other. The means for global knowledge range from 45.51 to 54.66 and the standard deviations range from 7.84 to 10.18 , indicating that the variances are slightly different from each other. The summary of the raw and transformed means and standard deviations of global knowledge by groups is presented in Table 3.

Table 3. Summary of Means of Raw Scores for Three Groups on Global Knowledge

\begin{tabular}{lllll}
\hline \multirow{2}{*}{ Group } & \multicolumn{2}{l}{ Raw Score } & & \multicolumn{2}{l}{ Standardized Score } \\
\cline { 2 - 5 } & $\boldsymbol{M}$ & $\boldsymbol{S D}$ & $\boldsymbol{M}$ & $\boldsymbol{S D}$ \\
\hline GOSSE & 29.93 & 7.02 & 54.66 & 10.66 \\
Non-GOSSE & 23.63 & 6.86 & 45.51 & 9.64 \\
TWTOS & 26.60 & 5.37 & 49.82 & 7.84 \\
\hline
\end{tabular}

The mean for Groupl $(M=29.93)$ was above the average raw score. The mean for Group $2(M=23.63)$ was below the raw average score. The mean for Group $3(M=$ 26.60) was average. However, as seen in Table 4 the scores for Global Mindedness reflect a different trend. Table 4 presents the summary of the raw and transformed means and standard deviations of global mindedness by groups. The overall average raw score for Global Mindedness is 105.42. The mean for Group1 $(M=103.97)$ was below the average raw score. The mean for Group $2(M=107.53)$ was above the raw average score. The mean for Group 3 ( $M$ $=$ 104.77) was average. An ANOVA test on the standardized data determined whether the differences are significant. The GOSSE group appears to have greater global knowledge than average but they are less globally minded.

Table 4. Summary of Means of Raw Scores for Three Groups on Global Mindedness

\begin{tabular}{lllll}
\hline & \multicolumn{2}{l}{ Raw Score } & & \multicolumn{2}{l}{ Standardized Score } \\
\cline { 2 - 5 } Group & $\boldsymbol{M}$ & $\boldsymbol{S D}$ & $\boldsymbol{M}$ & $\boldsymbol{S D}$ \\
GOSSE & 103.97 & 13.43 & 48.86 & 10.51 \\
Non-GOSSE & 107.53 & 12.82 & 51.65 & 10.02 \\
TWTOS & 104.77 & 12.22 & 49.48 & 9.56 \\
\hline
\end{tabular}

\subsection{Global Knowledge}

As shown in Table 5, there is a significant difference between groups: $F(2,87)=7.15, p<.05$ on global knowledge. The null hypothesis is, therefore, rejected. It is concluded that at least one group is different in their global knowledge. A Tukey post-hoc test was conducted to determine the loci of the difference and control for Type 1 error across the multiple pairwise comparisons. The posthoc revealed that GOSSE $(M=54.66)$, differs from nonGOSSE $(M=45.51)$ and TWTOS $(M=49.82)$ in the level of global knowledge. It is concluded that the mean scores for global knowledge for GOSSE was significantly higher on global knowledge than that of non-GOSSE and TWTOS groups. Table 5 presents a summary of the ANOVA of the interaction of Global Knowledge and Global Mindedness standardized scores. 
Table 5. Summary of ANOVA Showing the Interaction of Global Thinking and Group Membership

\begin{tabular}{|c|c|c|c|c|c|}
\hline Source & df & SS & MS & $\mathbf{F}$ & $\mathbf{p}$ \\
\hline \multicolumn{6}{|c|}{ Global Knowledge } \\
\hline Groups & 2 & 596.02 & 298.01 & 7.15 & $<.05$ \\
\hline MSEb & 87 & 3628.03 & & & \\
\hline \multicolumn{6}{|c|}{ Global Mindedness } \\
\hline Groups & 2 & 210.15 & 105.07 & .64 & $>.10$ \\
\hline MSEb & 87 & 14337.87 & & & \\
\hline Total & 89 & 4547.95 & & & \\
\hline
\end{tabular}

\subsection{Global Mindedness}

As shown in Table 3, there is no significant difference between groups: $F(2,87)=0.64, p<.10$ on global mindedness. The null hypothesis is not rejected. It is concluded that the mean scores for global mindedness of GOSSE $(M=48.86)$, although lower than non-GOSSE ( $M$ $=51.65)$, and TWTOS $(M=49.48)$ were not statistically different from each other.

\subsection{Main Effects}

An overall $3 \times 2 \times 2 \times(2)$ mixed analysis of variance (ANOVA) was conducted to determine the relationship between group membership, gender and years of teaching experience and Global Thinking. The between-subjects variables were: Group Membership (GOSSE, non-GOSSE, and TWTOS), Gender (female and male), and Years of Teaching Experience $(0-10$ and $11-20)$. The withinsubjects variable was the Global Thinking score (global knowledge and global mindedness). As shown in Table 4, the between subjects main effect of Group Membership (GM) was significant, $F(2,78)=2.43, p=0.09$, as was the interaction of GM and GT, $F(2,78)=5.59, p=0.05$. A Bonferroni post hoc comparison of the three means of main effect of Group Membership and the interaction of GM $\times$ GT, $F(1,78)=2.69, p=0.10$ showed that the mean for GOSSE $(M=54.66)$, was significantly higher than that for non-GOSSE $(M=45.51)$ and TWTOS $(M=49.82)$. None of the other main effects or interactions was significant.

The difference between non-GOSSE and TWTOS was not significant at $p<0.05$. Overall, this shows that teachers in the globally oriented program (GOSSE) had a higher level of mastery of global knowledge than teachers in the non-GOSSE and TWTOS program groups.

\subsection{Interaction of Groups and Global Thinking}

The main effect of Group Membership is qualified since the interaction of Group Membership and Global Thinking was significant, $F(2,78)=5.59, p<0.05$. To examine the loci of the interaction, the two components of Global Thinking (i.e., Global Knowledge and Global Mindedness) were analyzed, separately. In Table 6, the Summary of a mixed ANOVA of Global Thinking Scores is presented. In Table 7, the interaction of Global Thinking by Groups is also presented.

A two-way ANOVA of GOSSE and non-GOSSE programs and TWTOS are presented. There is a significant difference between GOSSE and non-GOSSE/TWTOS, $F$ (1, $88)=10.86$ on Global Thinking. The null hypothesis is, therefore, rejected.

Table 6. Summary Table of a Mixed ANOVA of Global Thinking Scores

\begin{tabular}{|c|c|c|c|c|}
\hline Source & $d f$ & $M S$ & $\boldsymbol{F}$ & $p$ \\
\hline & \multicolumn{4}{|c|}{ Between Subjects } \\
\hline Group Membership (GM) & 2 & 2.17 & 2.43 & .09 \\
\hline Gender (GE) & 1 & .04 & .04 & .95 \\
\hline $\begin{array}{l}\text { Years of Teaching } \\
\text { Experience }(E)\end{array}$ & 1 & .98 & 1.10 & .30 \\
\hline $\mathrm{GM} \times \mathrm{GE}$ & 2 & .68 & .76 & .47 \\
\hline $\mathrm{GM} \times \mathrm{E}$ & 2 & .09 & .11 & .90 \\
\hline $\mathrm{GE} \times \mathrm{E}$ & 1 & .53 & .59 & .45 \\
\hline $\mathrm{GM} \times \mathrm{GE} \times \mathrm{E}$ & 2 & .46 & .52 & .60 \\
\hline \multirow[t]{2}{*}{ MSEb } & 78 & .89 & & \\
\hline & \multicolumn{4}{|c|}{ Within Subjects } \\
\hline Global Thinking (GT) & 1 & .10 & .10 & .78 \\
\hline $\mathrm{GM} \times \mathrm{GT}$ & 2 & 5.65 & 5.59 & .05 \\
\hline $\mathrm{GE} \times \mathrm{GT}$ & 1 & 2.72 & 2.69 & .10 \\
\hline $\mathrm{E} \times \mathrm{GT}$ & 1 & 1.95 & 1.93 & .17 \\
\hline $\mathrm{GM} \times \mathrm{GE} \times \mathrm{GT}$ & 2 & 1.17 & 1.15 & .32 \\
\hline $\mathrm{GM} \times \mathrm{E} \times \mathrm{GT}$ & 2 & .13 & .13 & .27 \\
\hline $\mathrm{GE} \times \mathrm{GE} \times \mathrm{GT}$ & 1 & .13 & .14 & .71 \\
\hline $\mathrm{GM} \times \mathrm{GE} \times \mathrm{E} \times \mathrm{GT}$ & 2 & .89 & .88 & .42 \\
\hline MSEw & 78 & 1.01 & & \\
\hline
\end{tabular}

Note: Global Thinking is a combined score of global knowledge and global mindedness tests.

Table 7. Summary of ANOVA Showing the Interaction of Global Thinkingand GOSSE and Non-GOSSE and TWTOS

\begin{tabular}{|c|c|c|c|c|c|}
\hline Source & $d f$ & $S S$ & $M S$ & $\boldsymbol{F}$ & $P$ \\
\hline \multicolumn{6}{|c|}{ Global Knowledge } \\
\hline Groups & 1 & 997.65 & 977.65 & 10.86 & $<.01$ \\
\hline MSEb & 88 & 7922.35 & 90.03 & & \\
\hline \multicolumn{6}{|c|}{ Global Mindedness } \\
\hline Groups & 1 & 58.33 & 58.33 & .58 & $>.45$ \\
\hline MSEb & 88 & 8841.67 & 100.47 & & \\
\hline Total & 90 & 2333900.00 & & & \\
\hline
\end{tabular}

It is concluded that mean Global Thinking scores for the GOSSE program were significantly higher in their Global Thinking than that in non-GOSSE and TWTOS program means. The interaction between GOSSE and nonGOSSE/TWTOS was not significant, $F(1,88)=.58, p=$ 0.45 on global mindedness. It is concluded that teachers in GOSSE program were not different on their global mindedness than teachers in non-GOSSE/TWTOS.

\subsection{Survey Analysis Summary}

The analysis of the survey data indicates that teachers from the GOSSE program are significantly different in their level of global knowledge than those from non-GOSSE and in TWTOS programs. Therefore, Hypothesis 1 that stated that there is no significant difference among teachers in GOSSE, non-GOSSE, and TWTOS programs in their global knowledge is rejected. The hypothesis for global mindedness is not rejected. Hypothesis 2 that stated that there is no significant difference between teachers in GOSSE and non-GOSSE/TWTOS programs in their global knowledge and global mindedness is not rejected. 
Hypothesis 3 that stated that there is no significant difference between teachers in GOSSE and nonGOSSE/TWTOS in their global knowledge and global mindedness is not rejected. Hypothesis 4 regarding the relationship between degree, age, gender, and years of teaching experience is not rejected.

\section{Research Findings}

The findings of the study show that teachers who were trained in teaching from a global perspective differed in their global knowledge and used more appropriate instructional strategies than teachers who were not trained in teaching from global perspectives. There was no significant difference in the combined global knowledge of the non-GOSSE and TWTOS groups when compared with the GOSSE group. There was no significant difference in the combined global knowledge of the GOSSE and nonGOSSE groups when compared with the TWTOS group. There was no significant difference among the teachers in their global mindedness. Observation and interview data indicate that current events, role-playing, simulations, open-ended discussion, debates, and projects were the predominant instructional strategies used by globally trained teachers. Cable networks, Internet, magazines, and newspapers were found to be the dominant tools for teaching global education.

This study concluded that teachers who were trained in globally oriented programs had more global knowledge than teachers who were not. It is recommended that teacher education programs should incorporate a global perspective in the preparation of social studies teachers, with particular attention to developing their global perspective to assist them in their teaching delivery.

This paper presents the results of the study in two parts, quantitative and qualitative. In doing so, a brief description of the sample is given, followed by analyses of the data collected. Findings on the relationship between teachers' global knowledge, global mindedness, and instructional strategies are also presented. Because this study was intended to examine factors that contributed to teachers' global knowledge, global mindedness, and the instructional strategies used as well as the potential influences of degree, age, gender and years of teaching experience, the level of confidence was set at

$\alpha=.10$. However, for the post-hoc comparisons $\alpha=.05$ was used to control family-wise Type 1 error. To permit comparison and analyses of Global Knowledge and Global Mindedness (Global Thinking) scores in a mixed ANOVA, the two sets of raw scores were standardized (Gall, Gall, \& Borg, 1996).

\section{Discussion of Findings}

\subsection{Research Question \#1}

Is there a significant difference among teachers in
GOSSE, non-GOSSE, and TWTOS groups in their global knowledge and global mindedness? A significant difference was found between groups in global knowledge. Teachers in the GOSSE program group showed a higher level of mastery in their global knowledge than those in non-GOSSE and TWTOS groups. Therefore, the first null hypothesis was not rejected. However, since no significant difference was found in their global mindedness, this part of the null hypothesis was rejected.

\subsection{Research Question \#2}

Is there a significant difference between GOSSE and non-GOSSE/TWTOS groups in their global knowledge and global mindedness? No significant difference was found between GOSSE and non-GOSSE/TWTOS groups in their global mindedness. Therefore, the second null hypothesis was rejected. Teachers in the GOSSE group did not show a higher level of mastery in their global knowledge and global mindedness than those in non-GOSSE and TWTOS when the groups were combined.

\subsection{Research Question \#3}

Is there a significant difference between GOSSE/nonGOSSE and TWTOS groups in their global knowledge and global mindedness? Teachers in GOSSE/ non-GOSSE groups did not show a higher level of mastery in their global knowledge and global mindedness than those in the TWTOS group. Therefore, the third null hypothesis was rejected.

\subsection{Research Question \#4}

Is there a relationship between age, gender, degree, and years of teaching experience on global knowledge and global mindedness? No interactions were found between age, gender, and years of teaching experience on global knowledge and global mindedness. Therefore, the fourth null hypothesis was rejected.

\subsection{Research Question \#5}

Do teachers from the GOSSE group teach from a global perspective and infuse global perspectives into the curriculum differently than teachers from the non-GOSSE group? Teachers in both the GOSSE and non-GOSSE groups taught and infused global perspectives into the curriculum. They exhibited no difference in the level of infusion of global perspectives in their lessons. However, there was a major difference in the use of a conceptual framework or model to teach global education. The strategies frequently used by teachers in both groups were: issues-centered, role-playing, group activity, lecture, demonstration, and debate.

Discussion of Findings

The following questions form the framework for this section: (a) Does the teacher demonstrate knowledge of global knowledge, global mindedness, and global pedagogy? (b) Does the teacher allow for the exploration of global 
concepts and ideas, and discussion of current or controversial issues in the classroom? and (c) Does the teacher allow for the use of multiple perspectives, convergent, and divergent view points in the classroom? The following findings emerged from the data analysis.

First, training in teaching global education contributed to teachers' global knowledge. This finding was affirmed by the fact that teachers from the GOSSE program, on average scored higher on the global knowledge scale than teachers from the non-GOSSE programs and TWTOS group.

Second, teacher attitudes were not influenced by their participation in any particular global education programs. The implication of this finding is that changes in attitudes require different methods of instruction beyond those currently employed in institutions of higher education programs that are globally-oriented. Furthermore, since attitudes are more deeply embedded in cultural backgrounds and norms than in brief encounters with positive influences (such as those found in semester courses of instruction), sustained reinforcement efforts are required to produce enduring attitudinal change. Such efforts take time and should not only be infused in general teacher training curricula, but should also be continued through inservice workshops, seminars, and conferences for teachers. Although the GOSSE teacher group did have a higher global knowledge score, and lessons conveyed a more coherent theoretical framework, the lack of any difference in global attitudes noted in the survey results was reflected in similar global mindedness in classroom instruction. Furthermore, because the non-GOSSE teachers scored higher on the Global Mindedness scale than the GOSSE teachers, one may conclude that the globally oriented program the GOSSE teachers attended failed to meet at least one of its objectives.

Third, teachers who teach other subjects were not significantly different in their global knowledge and global mindedness than teachers from both GOSSE and nonGOSSE programs, when both groups were combined. This suggests that teachers who teach other subjects may have acquired global knowledge and global mindedness from several sources such as the media, magazines, peers, workshops, books, conferences, newspapers, and their own college experiences.

Fourth, no relationship existed between gender, degree, and years of teaching and teachers' global knowledge and global mindedness. This suggests that teachers' age, years of teaching, and gender do not affect teachers' global knowledge and global mindedness. Similarly, years of teaching and advanced degrees earned did not appear to increase these teachers' global knowledge and global mindedness. Finally, the data did not show any significant difference between the levels of global knowledge and global mindedness of male and female secondary teachers.

\subsection{Global Knowledge}

The findings showed that teachers who were trained in teaching from a global perspective had a higher level of global knowledge than teachers who were not trained in teaching from a global perspective. Findings from recent studies in global awareness and pedagogy conducted locally and nationally are consistent with the findings of this study.

\subsection{Global Pedagogy}

Observations were conducted, lesson plans were examined, and repeated conversations were held with teachers to answer the fifth research question, which focused on global pedagogy. Studies in global pedagogy conducted in Miami-Dade County and elsewhere support the findings of this study (Tucker, 1983). As in the literature, global classroom activities observed in this study included current events, role-playing, simulations, and discussion. Other typical global activities found both in the literature and observed in this study are problem-solving and decision making exercises. These activities provide students the opportunity to develop their cognitive, affective, and participatory skills (Diaz, Massialas, \& Xanthopoulas, 1999).

Diaz et al. (1999) believe that pedagogy for global education allows students experiences in the cognitive, affective, and participatory domains. They argue that in the cognitive domain, information and facts should be presented with concepts and themes. In the affective and participatory domains, learning activities should allow students to understand global events, issues, and problems from the perspectives of others. In participating in activities where they can demonstrate this understanding, students become more sensitive and empathetic. Furthermore, it follows that students should also become more knowledgeable about global events, issues, and problems when they participate in appropriate activities such as those indicated above. In the process students come have a deeper understanding of and appreciation for human and cultural differences and commonalities. This appreciation and understanding of other people and their world, is one of the core values of global education.

\section{Implication for Practice}

The study also has implications for enhancing local social studies teacher education programs, by providing information and ideas for improving teachers' global knowledge, global mindedness, and classroom practice in the M-DCPS. Additionally, the study will contribute to educators' understanding of the factors that may affect teachers' global thinking and classroom practices.

The implication is that changes in attitudes require different methods of instruction beyond those currently employed in preparing pre- and in-service teachers in globally-oriented programs. Furthermore, since attitudes are embedded in cultural backgrounds and norms, more than brief encounters with positive influences, such as those typically found in semester courses of instruction, are required to produce enduring attitudinal change. 


\section{Recommendations}

Based on the findings of this study, the following recommendations are offered:

1. To enhance global knowledge of social studies teachers, all social studies education programs should incorporate the study of current global realities as well as accomplished global instructional practices. This addresses the cognitive domain concerns of social studies teachers.

2. To address affective domain concerns raised in this study, social studies teacher education programs should all have more of an emphasis on global mindedness. This must be addressed more effectively in order to teach the whole teacher so that the teacher may teach the whole learner.

\section{Future Research}

Mixed Methods Research should now focus on gaining greater understanding of those elements that do influence teachers' global knowledge, global mindedness, and attitude. These mixed research elements must be integrated into college curricula so that teacher preparation programs have a better approach to influencing teachers' global knowledge, global mindedness, and attitudes than they now have. Effecting change in secondary school social studies content and methods depends on changing how teachers approach global education and its relationship to securing our global future.

\section{Conclusion}

Based on the findings of this study, the researcher concluded that the globally oriented social studies program did have an effect on teachers' acquisition of knowledge and the underlying conceptual clarity of their lessons, but did not have a significant effect on attitude change toward global education. Attitudinal change is critical in securing our local and global future. Youths of the world today are disconnected to the interconnectedness and interdependence of the universe and this may grave consequences in the long run. The researcher also concluded that the infusion of global knowledge and global mindedness in the teacher education curriculum with clear explanation of its use in the education will help young students to be motivated and inspired to want to contribute to securing our global future. Politicians and policy makers at the local and state levels should allocate appropriate funding for research and development in global or international education. It is therefore expected that the Florida International University, the Miami-Dade County Public Schools (M-DCPS), and the Federal University Kashere, Gombe, Nigeria will continue to the appropriate steps and the lead in promoting global learning, global education, and global citizenship.

\section{References}

[1] Abdullahi, S.A. (2010). Rethinking global education in the Twenty-first century. In J. Zajda (Ed.). Global pedagogies: schooling for the future (pp. 23-34). Dordrecht, New York: Springer.

[2] Abdullahi, S.A. (2004). Teacher's knowledge, awareness, and pedagogy of global education in secondary schools. Unpublished doctoral dissertation, Florida International University, Miami, FL.

[3] American Forum for Global Education (2002). Annual Report. New York: Author

[4] Anderson, L. F. (1990). A rationale for global education. In K.A. Tye (Ed.), Global education: From thought to action (pp. 13-34). Alexandria, VA: Association for Supervision and Curriculum Development.

[5] Educational Testing Service. (1981). Global Knowledge Scale. Princeton, NJ: Educational Testing Service.

[6] Friedman, L. T. (1999). The lexus and the olive tree: Understanding globalization. New York: Farrar, Straus \& Giroux.

[7] Global Education First Initiative (2011). Retrieved June 25, 2014, from http://www.globaleducationfirst.org html.

[8] Gutek, L. G. (2006). American education in a global society: International and comparative perspectives (2nd edition). Long Grove, IL: Waveland, Press, Inc

[9] Hanvey, R. (1976). An attainable global perspective. New York: Center for Global Perspectives.

[10] Hett, J. E. (1993). The development of an instrument to measure global-mindedness. Unpublished doctoral dissertation. University of San Diego, San Diego: CA.

[11] Jackson, R .J. (2003). Annual edition: Global issues. Boston: McGraw-Hill.

[12] Jackson, R .J. (2013). Annual edition: Global issues. Boston: McGraw-Hill.

[13] Kirkwood, T. F. (2001, January/February). Our global age requires global education: Clarifying definitional ambiguities. The Social Studies, 92, 10-15.

[14] Merryfield, M. (1991). Preparing American secondary social studies teachers to teach from a global perspective: Journal of Teacher Education, 42, 11-20.

[15] Merryfield, M. (1992). Preparing social studies teachers for the twenty-first century: Perspectives on effectiveness from a study of six exemplary teacher education programs in global education. Theory and Research in Social Education 20, 17-46.

[16] Merryfield, M. (1995). Institutionalizing cross-cultural experiences and international expertise in teacher education: The development and potential of a global education PDS network. Journal of Teacher Education, 46, 19-29.

[17] Merryfield, M. (2001). Moving the center of global education: From imperial world views that divide the world to double consciousness, contrapuntal pedagogy, hybridist, and cross-cultural competence. In B.W. Stanley (Ed.), Critical issues in social studies for the 21st century (pp. 179208). Greenwich, CT: Information Age Publishing. 
[18] Merryfield, M., \& Kasai, M. (2004). How are teachers responding to globalization? Research and Practice Social Education. 68, 354-359.

[19] Onwuegbuzie A.J. \& Johnson RB 2006. The validity issue in mixed research. Research in the Schools, 13:48-63.

[20] SPSS (2003). SPSS for Windows 11.1 [computer software]. Chicago: SPSS Inc.

[21] Tashakkori, A. \& Teddlie C. (1998). Mixed methodology: Combining qualitative and quantitative approaches. Thousand Oaks, CA: Sage Publications.

[22] Tashakkori, A \& Teddlie C (eds) 2003. Handbook of mixed methods in social and behavioral research. Thousand Oaks, CA: Sage.

[23] Tucker, J. L. (1991). Global education is essential to secondary school social studies. Bulletin, NASSE 75, 43-51.

[24] Tucker, J. L. (1993). Global perspectives for teachers: An urgent priority. Journal of Teacher Education, 42, 3-10.
[25] Tucker, J. L. (1990). Global change and American citizenship education: The vital role of history. Social Education, 54, 312-315.

[26] Tucker, J. L. (1991). Global education is essential to secondary school social studies. Bulletin, NASSE 75, 43-51.

[27] Tucker, J. L. (1993). Global perspectives for teachers: An urgent priority. Journal of Teacher Education, 42, 3-10.

[28] Zajda, J. (2010). Global pedagogies: schooling for the future. Dordrecht, New York: Springer.

[29] Zajda, J. (Ed.) (2010a). Globalization, education and social justice. Dordrecht: Springer.

[30] Zajda, J. (2005). The international handbook on globalization, education and policy research. Dordrecht, The Netherlands: Springer. 